\title{
The Dynamics of Urban Metabolism in the Face of Digitalization and Changing Lifestyles: Understanding and Influencing our Cities
}

\author{
Glenn Lyons ${ }^{1 \mathrm{a}}$, Patricia Mokhtarian ${ }^{2}$, Martin Dijst $^{3}$ and Lars Böcker ${ }^{4}$ \\ ${ }^{1}$ University of the West of England, Bristol, UK \\ ${ }^{2}$ Georgia Institute of Technology, Atlanta, USA \\ ${ }^{3}$ Utrecht University, Utrecht, Netherlands \\ ${ }^{4}$ University of Oslo, Oslo, Norway \\ ${ }^{a}$ Corresponding author: Faculty of Environment and Technology, University of the West of England, Frenchay \\ Campus, Bristol BS161QY. UK. Tel: +44 1173283219 Email: Glenn.Lyons@uwe.ac.uk
}

\begin{abstract}
The world's population continues to grow. With a trend of urbanisation apparent, increasing attention is now being given to understanding and shaping our cities to support an evolving society. Urban metabolism concerns the flows of material and non-material resources and wastes that characterise the functioning and sustainability of a city and which are fundamentally associated with human behaviour. This paper centres upon an examination of how the digital age is supporting and contributing to changing lifestyles and more particularly lifestyle expression. It shines a light on how a rapidly evolving telecommunications system is influencing, and has future potential to influence, how we participate in society with resultant consequences for urban stocks and flows. In particular, the paper considers the integration of digital technologies into everyday life (digitalization) and their influence both spatially and temporally on our engagement in working, leisure and shopping. It also considers the phenomenon of collaborative consumption in cities (whereby sharing of goods and services, facilitated by digitalization, creates yet further dynamics for urban metabolism). The paper reveals the highly complex and evolving nature of digitalization and collaborative consumption and associated challenges in defining, measuring and understanding the dynamics of human behaviour and social and business practices. In response to this it also considers the underpinning driver of urban metabolism - fulfilment of society's need or desire to access people, goods, services and opportunities. The paper outlines how different paths of urban development are now shaped by the inter-play between our land-use, transport and telecommunications systems and their use in terms of accessibility. Considerations for research and policymaking are highlighted which include the importance of addressing methodological issues in the face of a changing and uncertain future.
\end{abstract}




\section{Introduction}

Urban metabolism concerns the flows of material and non-material resources and wastes that characterise the functioning and sustainability of a city and which are fundamentally associated with human behaviour. This paper focuses on the changing nature of how people are living their lives as we move deeper into the digital age. Changing lifestyles are a fundamental determinant of the flows that arise, and will in the future arise, and affect urban metabolisms and their prospects for sustainability.

It is rather obvious that the world is becoming increasingly mobile. People are able to migrate voluntarily or are forced by political, economic and social turmoil in their countries of origin to other parts of the world. Supported by increasing affordability, business and tourist travellers are doing their 'business' elsewhere. At the day-to-day level, citizens are increasingly afforded flexibility in where, when and how they participate in activities as certain spatial and temporal constraints are relaxed and we combine physical travel and digital connectivity to engage socio-economically in society (Schwanen et al., 2008; Alexander et al., 2011). Perhaps paradoxically in this mobile world, urbanization levels globally are rising, suggesting a growing importance of proximity. Cities, which offer substantial opportunities to have interactions through physical proximity, are becoming increasingly the natural habitat of people (Steffen et al., 2007).

The worldwide economic, social, cultural and political globalisation and integration is a rather recent phenomenon. Yet the world is already from its origin an integrated natural system characterised by a vast collection of interacting physical, chemical and biological processes in the atmosphere, hydrosphere, geosphere and biosphere determining the state and evolution of the planet and life on it (UNEP, 2012). Although humans have inhabited our world for more than 200,000 years, since the latter part of the $18^{\text {th }}$ century human-driven emissions have become so pervasive and profound that they appear to rival the natural processes - and so began the Anthropogenic geological epoch (Crutzen, 2002; Steffen et al., 2007).

Cities, as the predominant habitat of the Anthropocene, have a major impact on the earth system: "Urban areas, which house half the world's population, utilize twothirds of global energy and produce 70 per cent of global carbon emissions (IEA 2008)" (UNEP, 2012, 18). With population growth and increasing urbanization, this footprint is set to increase tremendously. Understanding the drivers of social and economic spatio-temporal processes in interaction with the natural spatio-temporal processes in cities is of utmost importance to have options for a balanced future urban metabolism.

Consequently, the aim of this paper is to examine some major dynamics in lifestyles and some pathways for planning to accommodate uncertainty in lifestyle dynamics in the context of sustainable urban metabolism, resulting in recommendations for a research and policy agenda. Two research questions can be derived from this aim. First, "what are the potential implications of digitalization" and collaborative consumption for urban metabolism?" Changes in lifestyle orientations and

\footnotetext{
1 The integration of digital technologies into a set of activities or processes - in the context of this paper, into everyday life.
} 
expressions will affect future movements of people, consumer products and information as well as the nature of consumption. This could have large implications for the consumption of energy and other natural resources and the production of waste. Information and Communications Technologies (ICTs) have permeated into many people's urban lives and might affect the frequency and spatio-temporal pattern of physical activities and physical travel. The recent upsurge in collaborative consumption, which is related to increasing use of ICTs, holds the prospect of yet further (unknown) impact on urban metabolism (Botsman and Rogers, 2010).

"How can we accommodate uncertain lifestyle changes when planning for accessibility in the context of sustainable urban metabolism?" is the paper's second research question. Lifestyle changes take place in urban forms which change relatively slowly. There is a need to ensure that evolution of urban form is both flexible and resilient and occurs in such a way that uncertain longer-term futures for lifestyles and associated physical and digital connectivities can be accommodated and supported. At the same time, sustainable urban metabolism should be safeguarded. This calls for an appreciation of how society's fundamental needs and desires for access to people, goods, services and opportunities are fulfilled - through a combination of physical mobility, digital connectivity and spatial proximity - in a sustainable way. There is also a need to embrace the uncertainty over future access in terms of societal preferences and affordability - something which scenario planning offers a means of doing through its ability to foster group thinking, challenge preconceptions and account for key drivers of change in the development of plausible, divergent futures or pathways (Lyons et al., 2014).

By studying relevant literature, both research questions are addressed. In the next section, urban digitalization is discussed, followed by a section on collaborative consumption. In the fourth section the focus is on different pathways for urban development and their implications for urban metabolism. This paper is especially relevant for urban metabolism researchers from different scientific disciplines as well as policymakers addressing urban metabolism issues. In the interest of both target groups the paper concludes with a discussion of the key emergent issues and their implications in terms of future research and policy priorities.

\section{Urban digitalization}

It would be difficult to overstate the impact that ICTs have had on modern life. Countless activities that in the past could only be conducted in person, over a landline telephone, or by physically transporting a document or other object, can now be conducted digitally and/or remotely. In addition, ICTs have created numerous new activities that do not have close counterparts in the "pre-modern-ICT" era. Consider the following list of new or transformed activities, as only a small sample of the whole: teleworking, video meetings, monitoring the well-being of a dependent family member through a "nanny-cam", massive open online courses (MOOCs), multiplayer online games, online bill-paying and investing, income tax preparation, interacting with government agencies, communicating with social and professional networks, travel planning and purchasing, working or playing while traveling, music and video entertainment consumption, book/magazine/newspaper reading, photography, retailing, buying or renting a home, remotely controlling home utilities, and finding a personal service provider. Wearable computing, robotics/automation, and virtual and 
augmented realities are continuing the revolution. Although the geographic reach of these innovations is constantly growing, due to economies of scale they are often available first and most effectively within urban concentrations. Thus, without question, flows of bits and bytes within the urban metabolism have grown exponentially and forms of consumption of time and resources and of interaction have diversified and continue to do so.

In this section we first outline some of the research associated with selected "digitalized activities" that have been the subject of particular academic interest in relation to their implications for lifestyles and travel demand, namely teleworking, teleleisure, and online shopping. We then examine a key consequence of urban digitalization: the spatio-temporal fragmentation of activities enabled by ICT in general and the mobile internet in particular. We touch on how the picture varies with socioeconomic characteristics such as age and income, and finally speculate on some implications for use of resources and production of waste. To keep the scope manageable, the focus throughout is on the consumption choices made by end-users, and as such we neglect a vast landscape of ICTs involvement in the provision of goods and services (manufacturing, transportation, health care, and so on).

\subsection{Teleworking}

The past several decades have seen increasing portions of the jobs of white-collar information workers being digitalized, alongside the share of the workforce holding such jobs increasing markedly. Accordingly, telecommuting - working from home or from a location closer to home than the main workplace, in lieu of the regular commute - has long been promoted as an important tool for reducing peak period travel, with the accompanying benefits of reducing congestion, emissions, and fuel consumption among others.

A major challenge associated with studying teleworking is that the term can be applied to a number of rather diverse work arrangements (Mokhtarian and Tal, 2013) which in turn illustrate the collective complexity of lifestyles. The words "telecommuting" and "teleworking" are often used loosely, without defining what they mean in any particular context. However, the various forms of teleworking differ dramatically in their impacts on travel (and thence urban metabolism):

- from generally saving it in the case of substituters (the classic "telecommuters" salaried employees substituting working at home for commuting) and telecenterbased workers; to

- mostly neutral in the case of supplementers (those who bring work home to do on overtime), remote back office workers, field workers, and home-based selfemployed workers; to

- facilitating more travel in the case of mobile workers, and possibly in the cases of long-distance telecommuters and distributed team members.

The phenomenon of teleworking in the form of part-day homeworking and the temporal displacement rather than removal or reduction in length of the commute has also been identified (Haddad et al., 2009; Deng et al., 2015). 
This diversity of types of teleworking partly accounts for wide disparities in the estimates of how much is occurring, and difficulties in analysing trends over time (Mokhtarian et al., 2005). For example, the United Kingdom Labour Force Survey has measured home-based working over a number of years. In 2007, it reported 3.2 million homeworkers, of which 2.5 million (78\%) were defined as "teleworkers", i.e. using both a telephone and a computer to carry out work at home. This 2.5 million comprised $8.9 \%$ of the workforce, more than double the $4 \%$ share of 1997 . But $63 \%$ of those year 2007 teleworkers were self-employed or unpaid family workers, leaving $37 \%$ (about 925 thousand) as telecommuting salaried employees. On the other hand, all these worked "mainly" at home or in different places using home as a base, neglecting those who telecommute less frequently ${ }^{2}$. Later evidence indicates significant growth in UK homeworking has continued ${ }^{3}$. In the United States, the 2010 Survey of Income and Program Participation showed that 9.5\% of all workers worked entirely at home at least one day a week, up from $7.0 \%$ in 1997 . About $49 \%$ of the 9.5\% were salaried rather than self-employed or unpaid (Mateyka et al., 2012). Thus, teleworking has increased substantially over time (true also for the Netherlands ${ }^{4}$ ), although those engaged in the forms of teleworking most likely to reduce commute travel remain a small share of the total workforce.

Some recent studies have found that telecommuting is associated with more travel (Zhu, 2012; He and Hu, 2015), but it is not clear whether selection biases have been completely controlled for in those cases. The same studies show that telecommuting households differ from others on many other variables, and even after controlling for those variables in models of travel impacts, if the differences are too large, the impact estimates can still be biased (Imbens and Rubin, 2015). This is all the more true when telecommuters and non-telecommuters differ on unobserved variables (e.g. the specific nature of the occupation, attitudes toward risk or novelty) which are not explicitly controlled for at all.

\subsection{Teleleisure}

For approximately the last half of the twentieth century, leisure time has increased in developed economies, as incomes increased and as automation and other technological developments enabled reductions in time spent on certain work and household maintenance activities (e.g. Kuroda, 2010). Aguiar and Hurst (2009) put the average per capita increases in leisure time between 1965 and 2005 at 5 and 3.5 hours a week for men and women, respectively.

How have ICTs impacted the way we use our increasing leisure time? Mokhtarian et al. (2006) point out that use of ICTs can influence leisure activities in at least four different (and partly overlapping) ways: it can replace traditional means of conducting a similar leisure activity (such as downloading and reading an e-book instead of a physical one); it can generate new leisure activities, which either displace, augment, or overlay other activities (leisure or otherwise); it can save time by eliminating or streamlining other non-leisure activities (such as commuting, shopping, or bill-paying), with some of the saved time newly allocated to leisure; and it can be

\footnotetext{
${ }^{2} \mathrm{http}$ ://www.eurofound.europa.eu/observatories/eurwork/articles/telework-in-the-united-kingdom

3 http://www.ons.gov.uk/ons/dcp171776 365592.pdf

4 http://www.eurofound.europa.eu/observatories/eurwork/articles/telework-in-the-netherlands
} 
the instrument facilitating or modifying other leisure activities (such as impulsive meetings with friends).

Accordingly, although technological advances have undoubtedly increased the share of leisure time that is spent on ICT-mediated activities, specific numbers are difficult to compute in view of the definitional and measurement complexities involved (echoing our points above about teleworking). Numerous studies point to increases in ICT use in general (without distinguishing leisure activities from others), or increases in specific ICT-based leisure activities (some of which may overlay other activities, rather than taking time away from them), either in the population at large or in certain segments of it (e.g. Thulin and Vilhelmson, 2005).

Some scholars have speculated that the increase in ICT-based leisure activities could signify increasing isolation across society, with even ostensibly social interactions more often taking place "behind the screen" of a computer monitor or smartphone. Recent research, however, suggests that ICTs serve as a complement, with greater ICTs use associated with more time spent in-person with friends and family (e.g. Robinson and Martin, 2010; Nasi et al., 2012). In any event, the amount of travel conducted for leisure purposes does not appear to be diminishing as ICTs use increases. With respect to everyday travel, US statistics show that the share of person-trips reported for social-recreational purposes increased from $24.9 \%$ in 1995 (USDOT, 1997, Figure 10) to $27.5 \%$ in 2009 (USDOT, 2015, Figure 2-3), although the share of person-distance travelled remained relatively constant at $30.7 \%$ and $30.3 \%$, respectively. With respect to long-distance travel, tourism continues to increase by nearly every metric, in keeping with growth in personal incomes, the emergence of low-cost airlines, and - not to be overlooked - the role of ICTs in facilitating information-gathering, bargain-hunting, and connection with home while away (Dubois et al., 2011; White and White, 2007).

\subsection{Online shopping}

Online shopping has grown every year since statistics started being kept (around 2001): in May 2017 it constituted $15.9 \%$ of retail sales in Great Britain (up from $14.3 \%$ a year earlier) ${ }^{5}$, in the first quarter of 2017 it constituted $8.5 \%$ in the US (up from $7.8 \%$ a year earlier) ${ }^{6}$, and in the Netherlands the share was $8.5 \%$ in $2015^{7}$. As continued growth can be expected, the implications for urban metabolism will be complex (Mokhtarian, 2004). In the short term, questions revolve around the direct impacts on passenger travel and goods movement (as well as product packaging - see below), while in the long term, e-shopping will partly reshape retail geography and increase the globalization of markets.

In the short term, for example, to what extent is store shopping travel being replaced? The answer depends on whether a given online purchase actually replaces a store purchase, and if so, whether the store trip is/was made anyway (to browse without buying, or to buy other items), and if not, whether the forgone trip actually saves vehicle travel (which it will not, if the store is on the way to other destinations still

\footnotetext{
${ }^{5}$ https://www.ons.gov.uk/businessindustryandtrade/retailindustry/bulletins/retailsales/may2017

${ }^{6} \mathrm{https}: / / \mathrm{www} . c e n s u s . g o v / \mathrm{retail} / \mathrm{mrts} / \mathrm{www} / \mathrm{data} / \mathrm{pdf} / \mathrm{ec}$ current.pdf

7 https://www.thuiswinkel.org/bedrijven/nieuws/2871/online-consumentenbestedingen-groeien-in-het1e-halfjaar-van-2015-met-18-4
} 
being visited, nor if the forgone trip would not have involved a personal vehicle). Might shopping travel actually be generated? Potentially so, since social media could identify new shops to visit and online browsing could lead to store trips to try out merchandise before purchasing, while location-based marketing could prompt a special trip to take advantage of a personally-targeted bargain.

With respect to goods movement, it is clear that delivery trips increase with online shopping (although some purchased goods, such as music, software, and to some extent books, have dematerialized and do not require physical delivery). In addition, first time delivery attempts are not always successful leading to repeated delivery attempts. An important factor influencing resource consumption is the means of transportation used to deliver a product from the warehouse to the end-user (as well as geographic distance in a global online marketplace). As a generalization, air travel is far more energy-intensive than trucking which is more intensive than rail, so to the extent that the consumer demands rapid delivery, energy consumption increases (Hesse, 2002). Product packaging also differs between online and store shopping, which has further implications. Residential delivery of an item purchased online requires that it be packaged for the individual, which is far more resource-intensive than packaging a bundle of identical items for delivery to a store (Williams and Tagami, 2002; Matthews et al., 2001).

Over time, online shopping will affect the size, location, nature, and even existence of "bricks and mortar" stores, as well as warehouses and regional distribution centers (Hesse, 2002). Stores specializing in some products, such as movies, software, and travel, have already largely disappeared, and numerous bookstores have also succumbed. To the extent that retail outlets remain, but are consolidated so as to leave smaller markets underserved, residents in those markets must travel further to shop in stores (Visser and Lanzendorf, 2004). A number of speculations about the retail landscape have been advanced, such as that stores will become primarily showrooms allowing customers to experience goods before purchasing them online, that stores should add entertainment or other value beyond mere product acquisition in order to survive, that the "high street" is threatened, that malls are dead, that they are being reborn, and so on (Wrigley and Lambiri 2015). It is likely that all such speculations will be partly true. We also see now speculation over the role of drones in future delivery of certain goods, and the role of 3-D printing in the (very) local production of goods (although presumably still requiring delivery of the raw materials being printed) whose designs and 'right to print' may have been purchased online.

Over the long run, the ease with which the internet fosters the matching of sellers and buyers will also allow new, highly spatially distributed, markets to be cultivated. On the one hand, this may support the stimulation of developing economies (imagine the medium-scale production of village handcrafts and their sale around the world) and bring greater choice and control to remote markets (Freathy and Calderwood, 2013), but on the other hand, it may considerably lengthen supply chains and intensify local resource consumption. In sum, "as things currently stand, it cannot be stated with any degree of certainty that clicks are any more environmentally responsible than bricks" (Cullinane, 2009: 759). 


\subsection{Spatio-temporal fragmentation of activities}

The past few decades have seen computing platforms progress from room-size mainframes to laptops and tablets, telephones progress from landlines to mobiles, and the two technologies converge into smartphones more capable than the computers that guided the first moon landing. These smartphones have partially or completely replaced landline phones, laptops, televisions, radios, video recorders/players, audio recorders/players, cameras, newspapers/ magazines, watches, clocks, wallets, keys, calculators, notepads, maps, compasses, and flashlights, among other tools of daily life.

At the same time, the internet, which barely existed outside of defence and a few academic uses in 1990, has become the indispensable communication network and information repository of modern society. Initially, connection to the internet was achieved via computers and wirelines; now, access is widely achieved via smartphones and Wi-Fi or other wireless means. The resulting ability to access the internet increasingly from nearly everywhere, at any time, has released a number of spatio-temporal constraints on when and where many activities can be conducted. Further, we are now entering the era of the "Internet of Things", in which sensors embedded in material objects will communicate with other sensors to convey information, coordinate activities, and control functions and objects.

From the foregoing discussion, it is evident that ICTs use is both substituting for "old" activities and generating "new" ones. It is also important to realize that ICTs in general, and mobile internet in particular, are transforming not just the activities we do, but the way we do them. The increasing spatio-temporal fragmentation of activities was perceptively described in Couclelis (2000). She noted that whereas in the past, certain activities (work, school, shopping, socializing) tended to be conducted at certain times and places, today they are more and more taking on an "any time, any place" character. Furthermore, whereas formerly such activities tended to be conducted "one-at-a-time", today it is commonplace both to interleave working, shopping, and personal/social activities using fine-grained intervals, and to overlay multiple activities into the same time interval (Circella et al. 2012). Empirical analysis (Hubers et al., 2008; Alexander et al., 2010) indeed shows that greater ICTs use is associated with greater fragmentation, although socioeconomic differences may be more important. It is likely, however, that the available data is far from perfect, in view of the difficulties associated with fully capturing multiple simultaneous and/or short-duration activity fragments. Indeed, even the very definition of an activity has become more blurry with the increasing flexibility of "where, when, and how" to conduct them. This can make empirical determinations of cause-and-effect, and change-versus-stability, highly challenging.

These trends may have implications for attention span, productivity, and socialization that are beyond the scope of this paper. What is relevant to our scope is the impact of fragmentation on resource consumption in general, and travel in particular. Empirical evidence is still relatively scant, but it seems that such trends could lead to more travel, through mechanisms such as allowing travel time to be used more productively, reducing the pain of absence, and directly stimulating the desire to travel (Mokhtarian and Tal, 2013). 


\subsection{Population heterogeneity}

To keep the scope manageable, this section has focused primarily on general trends, applicable to much of the developed world as an average tendency. However, it is clear that there is significant variability, even within developed countries and certainly between developed and developing countries, in the access to advanced ICTs and the ability (or confidence) to use them. Within developed countries, the elderly and lowincome segments of the population are less likely to own computers, to have broadband internet access at home, and to use the internet. In developing countries, mobile telephony (including the mobile internet) has sometimes leapfrogged its older landline counterpart, so that internet access is more widespread than might be expected (Pearce and Rice, 2013), even if far from equivalent to its personal computer counterpart (Napoli and Obar, 2013). In such contexts, smartphones are being used to develop and run small businesses, and economical computers are being put to use in schools and homes. Despite those encouraging developments, the digital divide is still quite real, and future research should not ignore its implications.

It is also important to consider the evolution of ICTs impacts over time, as embodied in the choices of future generations. A wide variety of futures is imaginable, depending on the extent to which economic prosperity promotes increasing marginal consumption of resources, while the regulations of governments and the selfregulation of personal commitments to a sustainable lifestyle promote greater conservation and reuse of resources.

\subsection{Implications for resource use and waste production}

At several points so far in the paper, we have alluded to some implications of digitalization for energy and resource consumption and (implicitly) waste production. These consequences appear to be complex. The case of travel, as a major consumer of resources, is typical. Certainly, ICTs use replaces some travel (and thence reduces petroleum consumption), but we have highlighted a number of ways in which it can increase travel as well. With respect to other resources, the dematerialization of books and music has clearly reduced the consumption of energy and other resources for those goods (although its contribution to the production and energy consumption of new products such as e-readers, headphones, and other accessories, must also be accounted for). However, online shopping may well increase overall goods consumption, for example by increasing price competition, through more targeted advertising, by lengthening the international reach of small producers, and by strengthening social influence (e.g. through Facebook "likes" and other social network exposure). In addition, as previously discussed, the packaging required for the delivery of 100 books individually is considerably higher than that required to deliver a single box of books to a warehouse and then to a store.

It becomes apparent from our examination of urban digitalization that it is almost impossible to isolate and study particular digitally-influenced behaviours and in turn understand their change over time, or indeed how many such behaviours interact and culminate in aggregate effects upon flows of material and non-material resources. This poses a major analytical challenge if indeed we believe, as we have done in the past, that we can empirically study and model individual behaviours in order to provide both insight and foresight regarding how our urban systems are performing 
and developing. We return later in our paper to examining how we can address this in ways that can usefully inform the development of our urban systems and ensure a healthy urban metabolism.

We now turn to the notion of collaborative consumption and the possibility that some of the effects set out in this section might be countered or further influenced by the rise of the sharing economy.

\section{Collaborative consumption in cities}

\subsection{Collaborative consumption}

Recently, the phenomenon of collaborative consumption, in which products, services and information are shared via Business-to-Business (B2B), Business-to-Consumer (B2C) or Peer-to-Peer (P2P) markets, has grown rapidly (Botsman and Rogers, 2010). Triggered by the 2008 economic crisis and growing environmental concerns, and enabled by new advancements in ICTs, traditional patterns of conspicuous consumption have increasingly been challenged by mechanisms that value access to goods and services more highly than ownership (Rifkin, 2000). Recently popularised examples include accommodation sharing (Airbnb), car sharing (Zipcar), ride sharing (Uber), bike sharing (Bicing), tool lending (Tool Libraries) and task outsourcing (TaskRabbit) (Burnett, 2014; Botsman, 2013; Fishman, 2015).

However, collaborative consumption is not a new phenomenon. Before the industrial revolution, informal sharing, bartering, lending and gifting of products and services amongst family, relatives, friends and neighbours were quite common in agriculturalbased societies (Belk, 2007; Rifkin, 2014). In the modern market-economy, involving private ownership of commodities and trade via anonymous financial transactions, sharing as a mechanism for distribution and consumption has almost completely been erased. Today's upsurge in collaborative consumption (which differs from the preindustrial informal sharing in that it involves wide-scale sharing amongst complete strangers (generally enabled by ICTs)) may change this current socio-economic paradigm (Gansky, 2010).

With its recent growth and positive connotation, sharing has become an ambiguous concept, increasingly, and often wrongfully, used to describe a plethora of new business initiatives (Belk, 2014a). According to Belk (2007: 127), true sharing can be defined as "the act and process of distributing what is ours to others for their use" or vice versa, takes place within communities, and is linked to altruistic motivations (Belk, 2014a). Other more extrinsically motivated exchanges of goods and services, such as those that involve a financial transaction, he refers to as pseudo sharing (Belk 2014a). Other scholars make a less strict distinction, and point out that both monetary and non-monetary sharing result from a combination of intrinsic (e.g. altruism, environmentalism) and extrinsic (e.g. economic, convenience) motivations (e.g. Piscicelli et al., 2015; Hamari et al., 2013). For an empirical examination of 24 potential motives for sharing, see Hawlitschek et al. (2016).

Motivations may differ for different types of shared goods and services. Economic incentives, often linked to the 2008 economic crisis, have been reported as the most important motivation to participate amongst users of the car-sharing scheme Zipcar 
(Bardhi \& Eckhardt, 2012) and the accommodation-sharing platform Airbnb (Tussyadiah, 2015). In other sectors, such as for the 'stuff-sharing' platform Ecomodo (Piscicelli et al., 2015), environmental reasons to participate appear to be more prominent. Finally, as especially peer-to-peer sharing often involves direct interactions between users and providers, sharing is often linked to social motivations. Social aspects have for instance been reported as an important factor for toy library (Ozanne and Ozanne, 2011) and Airbnb participation (Tussyadiah, 2015). In a recent stated preference study from the Netherlands, Böcker and Meelen (2017) crosscompare motivations for the intended participation as user and provider in different sectors of the sharing economy (Figure 1). They conclude that economic incentives are relatively important for the use of shared physical assets such as cars, accommodation and tools; environmental incentives for car and especially ride sharing; and social incentives for the more personal service of meal sharing. Moreover, except for accommodation sharing, providing your own assets for sharing is less economically motivated than using others'. Additionally, the authors indicate that motivations may differ between population categories. For instance, younger people seem to be more economically motivated than older people and women more environmentally motivated than men.

Figure 1: Motivations to use and provide shared assets for different social groups and sectors (Böcker and Meelen, 2017)

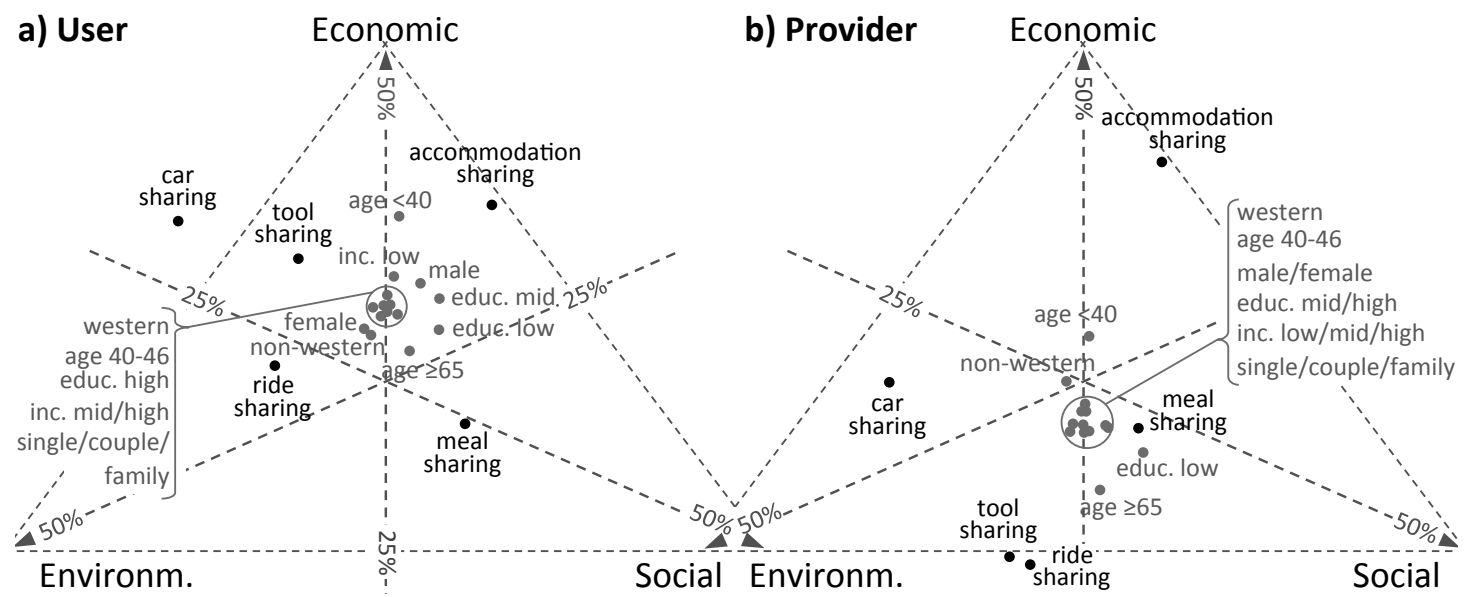

Percentage axes in the triangle indicate the relative importance of environmental, economic and social motivations. A central position indicates all three are equally balanced; locations away from a corner indicate a lower importance of that motivation.

Despite the vast interest in collaborative consumption, insights into users' profiles are relatively limited and ambiguous (e.g. Grassmuck, 2012). Collaborative consumption is often thought of as attracting mostly younger people, or millennials (The Atlantic, 2012; Shareable, 2012). As is reported for other technological (e.g. Czaja et al., 2006) or societal (e.g. Cornelis et al., 2009) innovations, reasons for a lower participation amongst older generations may include their lack of familiarity, knowledge, skills and/or comfort. A global internet survey shows that of respondents willing to participate in share communities, $35 \%$ are aged $21-34$ and $17 \%$ are aged $35-49$ (Nielsen, 2014). Some earlier studies, for instance amongst car sharers (Millard-Ball et al., 2005), reached similar conclusions, although others, for instance amongst members of the stuff sharing platform Ecomodo, find highest participation rates 
amongst middle aged people (Piscicelli et al., 2015). Regarding gender, Millard-Ball et al. (2005) report that men are more likely to share cars, while Piscicelli et al. (2015) find higher stuff-sharing participations amongst women. Both studies report higher sharing rates amongst the higher educated. Regarding household type, some studies show that singles are more likely to participate in car sharing than families (Celsor and Millard-Ball, 2007). Contradictory findings can be observed with regard to household income. A North American car sharing study reports a positive effect of income on sharing (Burkhardt \& Millard-Ball (2006), whereas a later car sharing study from Texas indicates a negative effect (Zhou and Kockelman, 2011). Higher adoption rates amongst higher income groups could be a result of the means they have to experiment with new innovations (Rogers, 2010) or of the greater number of goods they have available to share (Meelen et al., in progress). On the other hand, monetary incentives for both using (Litman, 2000; Fishman, 2015) and providing (Fraiberger and Sundararajan, 2015) shared assets are relatively higher for low-income groups.

These different and often contradicting findings on user profiles cast some doubts about how, and the extent to which, socio-demographic factors affect patterns of sharing. To investigate this, a second recent stated preference study from the Netherlands (Meelen et al., in progress) investigates how socio-demographic factors affect the intended use and provision of shared assets, not only directly, but also indirectly via the lifestyle-related factors environmental consciousness, social engagement and neighbourhood attachment. The authors confirm some of the abovementioned findings, such as that men, older people, higher educated and lower income groups are less likely to participate in the sharing economy, when looking at total effects. However, the authors statistically demonstrate that most of the variance in these effects is intermediated by social engagement and especially the environmental consciousness, both of which strongly enhance the willingness to use or provide shared assets. Moreover, the authors argue that willingness to participate and user profiles differ significantly between users and providers, as well as between different sectors of the sharing economy. A new finding is that non-western immigrants are significantly more likely to share accommodation, gardens and meals, although such effects cannot be found with regard to car, ride and tool sharing. This could be related to different norms, identities and lifestyles towards hospitality in nonwestern cultures, Arab in particular (Sobh and Belk, 2011), as compared to western cultures.

The importance of lifestyles and cultures for sharing practises is further elaborated upon by Belk (2007: 130), who states that: "[s]haring is a cultural learned behaviour. The same is true of possession and ownership". In western countries via upbringing, education and socialisation in general, citizens have learned to value possession and ownership and to exchange goods and service via money transactions. Persons in these cultures might "...feel a possession is a part of our extended self..." (o.c.: 131) which becomes part of their identity. Although privatization of possessions has left its mark, sharing is still an important phenomenon in western families. Different socialisation processes in non-western countries have put much less emphasis on ownership of goods and have stimulated sharing as the norm (o.c.). These cultural differences are also reflected in uneven penetration of sharing economies throughout the world. Nielsen (2014) has shown that more than two-thirds of global online consumers are willing to share or rent personal products or services in a sharing 
economy, but that these shares are higher in Asia-Pacific (about 80\%), Latin America and Middle East/Africa (about 70\%) than in western countries (about 50\%).

\subsection{Collaborative consumption and urban metabolism}

From an urban metabolism perspective, the question is what the potential implications of collaborative consumption are for mobility patterns and the nature of consumption. According to Botsman and Rogers (2010) but also Rifkin (2000; 2014), collaborative consumption could result in more efficient use of energy and other natural resources and less waste. In Table 1, for various sharing initiatives, we hypothesize the potential energy and resource savings, rebound effects and mobility flows. Some of these implications are highly permeated by uncertainty, but could be a starting point for future research.

The environmental (and thence urban metabolic) implications of collaborative consumption are most frequently documented for shared mobility. Studies, although not always publically funded and often based on data commissioned by car sharing firms (Kent, 2013), indicate that car and ride sharing lead to important reductions in car ownership and usage. It is estimated that the introduction of one shared car may lead to a reduction of between four to twenty or more owned cars (e.g. Shaneen and Cohen, 2007; Martin et al. 2010; Siou et al., 2013), as well as reductions in travelled distances by car (e.g. Martin and Shaheen 2010; Kent, 2013) of up to 44\% (Shaneen et al., 2009) and $\mathrm{CO}_{2}$-emissions in the range of $142-312 \mathrm{~kg}$ per person per year (Haefeli et al., 2006; Wilke et al., 2007; Martin, et al., 2010). Trips in shared cars require better planning, possibly reducing the number of impulse trips. Additionally, as the fixed costs of vehicle ownership are replaced by variable costs, people may be more reflexive on estimating the necessity of each car trip and may better compare alternative transport modes (Duncan, 2011; Kent, 2013; Siou et al., 2013). However, car and ride sharing may also give those who would otherwise not be able or willing to afford access to a (second) car to do so (Litman, 2000; Kent, 2013). This was precisely the aim of the world's first car sharing schemes in the $20^{\text {th }}$ century (Hald et al 2010), possibly inducing car usage. With regard to ride sharing, the net environmental impacts may differ substantially between car/ride pooling schemes and chauffeured on demand ride (or taxi) services like Uber. In the first those 'who are travelling in the same direction anyway' use one instead of two or more vehicles, thereby reducing per-occupant fuel consumption and emissions. The latter is less resource efficient as it generates new on demand chauffeured and idle rides.

While shared mobility studies focus mostly on aggregated $\mathrm{CO}_{2}$-emission reductions, other urban metabolic implications are less well documented. Little is known on how shared mobility adoption affects daily mobility decisions and lifestyles on a disaggregated level, including trip scheduling, destination choice, routing, transport mode and vehicle choices, and how this could relieve or enhances local environmental stress and congestion in urban regions. For instance, the net environmental and congestion-reducing benefits of bike sharing depend on whether it is considered a good substitute for private vehicle ownership and usage, and whether it is wellintegrated with public transport, cycling and pedestrian infrastructures, so that it enhances rather than substitutes trips by public transport and foot (Fishman, 2015). 
The environmental impacts of other forms of collaborative consumption have received less attention. Peer-to-peer accommodation sharing schemes, such as Airbnb, have a potential to be more resource efficient than hotels. When renting otherwise unused parts of other peoples' dwellings, more efficient use is made of the existing building stock, which could reduce the need to construct new hotels. However, such idle-capacity benefits do not hold when estate owners buy up multiple apartments, with the sole purpose of short-term letting. Moreover, any potential positive resource efficiencies may be counteracted by induced leisure and business travel thanks to cheaper overnight stays (Tussyadiah and Pesonen, 2015). Additionally, those renting their own accommodation while on holiday could potentially use the earned rent to kick-start more expensive, distant, and resource intensive holidays than they would otherwise be willing or able to afford. Access to garden sharing schemes could reduce the need for urban citizens to privately own larger (less resource-efficient) dwellings with gardens. Additionally, it may lead to increased local low-carbon food consumption, reduction of carbon emissions in food transport, increased food self-sufficiency of cities, more sustainable and healthy food cultures and lifestyles, and increased social cohesion in the neighbourhood.

Table 1: Urban Metabolism implications for different sectors in the sharing economy

\begin{tabular}{|c|c|c|c|c|}
\hline & $\begin{array}{l}\text { Potential energy and } \\
\text { resource savings in } \\
\text { production process }\end{array}$ & $\begin{array}{l}\text { Potential energy and } \\
\text { resource savings from } \\
\text { usage patterns }\end{array}$ & $\begin{array}{l}\text { Potential rebound } \\
\text { effects }\end{array}$ & $\begin{array}{l}\text { Implications for the flows } \\
\text { of different goods and } \\
\text { people }\end{array}$ \\
\hline $\begin{array}{l}\text { Car } \\
\text { sharing }\end{array}$ & $\begin{array}{l}\text { - Studies indicate } \\
\text { reductions in }(2 \mathrm{nd}) \\
\text { car owner-ship and } \\
\text { energy savings } \\
\text { embodied within the } \\
\text { manufacturing of } \\
\text { cars. }\end{array}$ & $\begin{array}{l}\text { - Studies point out net } \\
\text { reductions in distances } \\
\text { travelled by car } \\
\text { (Vehicle Miles } \\
\text { Travelled - VMT) }\end{array}$ & $\begin{array}{l}\text { - Could attract non- } \\
\text { car owners away } \\
\text { from active or } \\
\text { public transport } \\
\text { modes }\end{array}$ & $\begin{array}{l}\text { - Net reductions in VMT, } \\
\text { but less is known about } \\
\text { its effects on wider } \\
\text { spatio-temporal mobility } \\
\text { patterns and congestion }\end{array}$ \\
\hline $\begin{array}{l}\text { Ride } \\
\text { sharing }\end{array}$ & $\begin{array}{l}\text { Could be alternative } \\
\text { to (2nd) car } \\
\text { ownership, for } \\
\text { incidental users, with } \\
\text { embodied energy } \\
\text { savings }\end{array}$ & $\begin{array}{l}\text { - Pooling of rides lowers } \\
\text { per occupant energy } \\
\text { usage and vehicle } \\
\text { emissions }\end{array}$ & $\begin{array}{l}\text { - On demand taxi } \\
\text { services (e.g. } \\
\text { Uber-pop) } \\
\text { generate new } \\
\text { occupied/idle rides }\end{array}$ & $\begin{array}{l}\text { - Net effects are uncertain } \\
\text { and depend on business } \\
\text { model (pooling of } \\
\text { existing rides or on- } \\
\text { demand taxi) }\end{array}$ \\
\hline $\begin{array}{l}\text { Bike } \\
\text { sharing }\end{array}$ & $\begin{array}{l}\text { - No direct savings, but } \\
\text { could strengthen } \\
\text { public transport or } \\
\text { cycling and be part of } \\
\text { a transition towards } \\
\text { low energy mobility, } \\
\text { with indirectly } \\
\text { reductions in car } \\
\text { ownership and } \\
\text { embodied energy }\end{array}$ & $\begin{array}{l}\text { Potentially reduces } \\
\text { VMT by substituting } \\
\text { car travel or by } \\
\text { reinforcing public } \\
\text { transport } \\
\text { - May also substitute } \\
\text { walking or public } \\
\text { transport with lower } \\
\text { energy savings as a } \\
\text { result } \\
\text { - Little empirical } \\
\text { evidence so far on } \\
\text { cross-modal effects }\end{array}$ & - $\mathrm{n} / \mathrm{a}$ & $\begin{array}{l}\text { - Could reinforce public } \\
\text { transport if integrated } \\
\text { adequately into a } \\
\text { multimodal system } \\
\text { - Could trigger further } \\
\text { cycling investments and } \\
\text { improve conditions by } \\
\text { safety in numbers } \\
\text { - Limited socio- } \\
\text { demographic diversity in } \\
\text { user profiles }\end{array}$ \\
\hline $\begin{array}{l}\text { Accom- } \\
\text { moda- } \\
\text { tion } \\
\text { sharing }\end{array}$ & $\begin{array}{l}\text { Savings in building } \\
\text { construction } \\
\text { resources thanks to } \\
\text { efficient use of idle } \\
\text { capacity in buildings } \\
\text { - Effects could be } \\
\text { opposite if landlords }\end{array}$ & $\begin{array}{l}\text { - Staying in idle rooms in } \\
\text { houses is less resource } \\
\text { intensive than staying } \\
\text { in hotels. But staying in } \\
\text { apartments bought with } \\
\text { purpose of renting out } \\
\text { may not be. }\end{array}$ & $\begin{array}{l}\text { - Cheaper overnight } \\
\text { stays could induce } \\
\text { long distance } \\
\text { travel } \\
\text { - Renting out homes } \\
\text { could provide } \\
\text { finance to kick- }\end{array}$ & $\begin{array}{l}\text { - Induced long distance } \\
\text { business travel and } \\
\text { tourism } \\
\text { - Higher housing prices } \\
\text { and nuisance by tourists, } \\
\text { could force residents } \\
\text { away from inner-city }\end{array}$ \\
\hline
\end{tabular}




\begin{tabular}{|c|c|c|c|c|}
\hline & $\begin{array}{l}\text { buy new property } \\
\text { with a purpose of } \\
\text { short-term renting out }\end{array}$ & $\begin{array}{l}\text { - Rebound effects are } \\
\text { likely to outweigh } \\
\text { possible savings } \\
\end{array}$ & $\begin{array}{l}\text { start long distance } \\
\text { holidays }\end{array}$ & $\begin{array}{l}\text { areas. Potentially leads to } \\
\text { longer commutes and } \\
\text { induced daily travel. }\end{array}$ \\
\hline $\begin{array}{l}\text { Garden } \\
\text { sharing }\end{array}$ & $\begin{array}{l}\text { Could reduce large } \\
\text { dwelling + garden } \\
\text { ownership. } \\
\text { - Could enhance local, } \\
\text { carbon-efficient food } \\
\text { consumption }\end{array}$ & $\begin{array}{l}\text { Could reduce transport } \\
\text { emissions in food sector }\end{array}$ & - $\mathrm{n} / \mathrm{a}$ & $\begin{array}{l}\text { - Could reduce global/ } \\
\text { regional transport of food }\end{array}$ \\
\hline
\end{tabular}

\section{Pathways for urban developments}

The previous sections of the paper have highlighted the complex nature of urban living and the presence of important and potentially transformative dynamics in terms of the forms of participation in society and the implications for flows and overall consumption of resources. The evidence that continues to emerge in relation to the study of socio-economic activity in this dynamic setting can be perplexing. Things are changing over time and are different according to social, spatial, cultural and demographic settings. Evidence can appear contradictory or ambiguous because of different settings, challenges of definition, difficulties in observing and understanding behaviours and the complex inter-play between different behaviours. In this section of the paper we therefore adopt a different approach by considering the broader framework within which this complexity plays out. We examine how lifestyles are expressed and enabled by different forms of access to people, goods, services and opportunities. We consider the uncertainty in relation to potentially changing lifestyles and how this can be exposed by scenario planning and then acted upon by those responsible for shaping urban development.

\subsection{Needs and desires versus resources and opportunities}

An urban metabolism is strongly characterised by supply-side and demand-side factors. By supply-side we mean the availability of resources that enable people to live their lives, interact and consume. Resources include physical infrastructure (roads, vehicles, telecommunications, housing and other forms of land use) as well as the means to make use of that infrastructure (financial, physical, legal, intellectual etc.). By demand-side we mean the need or desire for people individually and collectively to lead their lives, interact and consume in particular ways. Supply and demand sides are co-evolving, mediated by the policies and investment decisions of public and private sector bodies. Two questions help frame our outlook concerning possible pathways for urban developments: (i) what will people in future be able to (afford to) do? (supply-side); and (ii) what will people in future want or need to do? (demand-side) (Lyons et al., 2014). The urban metabolism is the manifestation of stocks and flows (energy, traffic, water, capital, air pollution, materials, information, social capital, culture etc.) that derive from supply and demand.

Van Acker et al. (2014) distinguish between lifestyle and lifestyle expression, clarifying that "observable patterns of behaviour (lifestyle expressions) are explained by underlying opinions and orientations (lifestyles)" (Van Acker et al., 2014: 10). Lifestyle expression is a result of what people want to do (demand) mediated by what they are able to do (supply). As such, lifestyles strongly underpin urban metabolism. 
For many years, urban supply and demand have played out significantly in terms of how our cities have been shaped and dominated by the private car. More recently in many European cities, efforts have increased to kerb such dominance ${ }^{8}$. As we have set out in Section 3, collaborative consumption is now a potentially transformative phenomenon in terms of means of mobility in urban areas. Shared ownership or no ownership at all has the possibility of fundamentally changing the number of motorised and non-motorised vehicles in urban areas, how they are used and how much they are used. Quite possibly linked both to urban digitalization as well as to a re-emergence of collaborative consumption is the recent phenomenon of peak car (Goodwin, 2012; Goodwin and Van Dender, 2013). This phenomenon raises the question of whether or not lifestyles are changing rather fundamentally and it may signal the manifestation of such changing behaviours as outlined in the previous two sections.

'Peak car' is a shorthand term for the observed interruption in a number of developed economies with mature transport systems of the long-run trend in growing car use and the question over whether or not car use has peaked. The future remains unclear with regard to whether or not, at the aggregate, car use per capita and total car travel (the latter affected by changing population size) will resume its earlier trend in growth, remain plateaued (or saturated) or move into decline (i.e. have peaked). Nevertheless, across several countries, from 2004 to 2014, total car travel (vehicle miles travelled) did not increase. More recently, fuel prices have been driven down by a tumble in world oil prices and, coupled with signs of economic recovery, there has been some resumption in growth in total car traffic. However, the future demand for car travel remains uncertain.

It is recognised for a number of countries that when change in car use is examined at a disaggregated level, two factors emerge as important to changes in car use: age and location. Fewer young adults over time are acquiring a driving licence and per capita driving amongst young people is going down (Delbosc and Currie, 2013). Car use per capita in urban areas is going down while the reverse is true in rural areas (e.g. London has seen a reduction over a ten-year period of $20 \%$ in annual car mileage per resident (Le Vine and Jones, 2012)). Berrington and Mikolai (2014) have explored the possibility that young people's reduction in licence holding and car driving may be associated with a delayed transition to adulthood. "Many young people are staying in education longer, entering employment later and making the transition to residential independence, partnership and parenthood at older ages" (Berrington and Mikolai, 2014: ii). It has also been posited that the national policy in the UK in recent years to increase the proportion of people going into higher education may be an important contributor. Young people spend 3-5 years living in urban areas in settings where they and their peers are discouraged from or unable to (afford to) own a car and in turn develop norms of attitude and consumption behaviour that are not car dependent (Lyons and Goodwin, 2014) or are more greatly focused upon notions of shared resource.

\footnotetext{
${ }^{8}$ http://www.theguardian.com/cities/2015/apr/28/end-of-the-car-age-how-cities-outgrew-theautomobile
} 
It remains unclear whether declining car use amongst young urban dwellers is a reflection of lifestyle change or of demand-side constraints (limited capacity to accommodate any growth in car traffic and limited affordability of being able to drive). Greater clarity would provide important clues for urban development. Examination of changing car use is also giving rise to the question of how digital connectivity may be playing its part in reducing reliance upon and perhaps even the appeal of car ownership and/or use (Le Vine and Jones, 2012; Van der Waard et al, 2013; Lyons, 2015; Van Wee, 2015).

The peak car phenomenon underlines that lifestyles or at least lifestyle expression may be undergoing significant change that will affect urban metabolism. However, it also highlights our inability, as yet, to adequately understand changes that are taking place, thus presenting us with uncertainty. To manage such uncertainty requires that we acknowledge the key underpinning phenomenon to urban development - namely society's need or desire for access - an ability to reach people, goods, services and opportunities.

\subsection{Accessibility as the key underpinning phenomenon to urban development}

Digital connectivity is a rapidly growing phenomenon in society and it sits alongside physical mobility and spatial proximity as an important means of providing access (to people, goods, services and opportunities) and thus contributing to lifestyle expression. This has already been made apparent in Section 2. Accessibility (the means to gain access) can be expressed in its simplest terms as 'get-at-ableness' (Farrington, 2007: 320); or as defined by Abley and Halden (2013: 7) "the ease with which activities, either economic or social, can be reached or accessed by people". When considered from a social welfare perspective, accessibility concerns asking "can people can get to key services at reasonable cost, in reasonable time and with reasonable ease?" (SEU, 2003: 1). Geurs and van Wee (2004) identify four components to accessibility: land-use (location and extent of opportunity supply and demand); transport (movement and its 'cost' in transcending distance); temporal (when opportunities are available and people are available to take them up); and individual (needs, abilities and means for connecting with opportunities). Importantly, digital connectivity impacts upon these four components through the creation of virtual mobility (Kenyon et al., 2003), as explored in Section 2.

Urban development is fundamentally shaped by the system of accessibility which itself comprises the transport system, the land use system and the telecommunications system (referred to by Lyons and Davidson (2016) as the 'Triple Access System'). Supply-side actors will influence this three-pronged system of accessibility, which will influence and be influenced by the demand-side consumers. Inter-relations within the overall system can be briefly outlined as follows:

Transport and land-use: Closeness in terms of the land use system can reduce a reliance on the transport system in terms of achieving access and can produce agglomeration benefits (Graham, 2006). Rode et al. (2014) in their examination of transport and urban form highlight the phenomenon of different accessibility pathways which vary according to the relative role of physical proximity or transport solutions in providing accessibility. They make the distinction between "walkable, 
public transport-based compact cities" and "sprawling car-oriented cities" (Rode et al., 2014: 5) (see Table 2).

Table 2. Comparison of cities with different accessibility pathways (data from Rode et al., 2014)

\begin{tabular}{|c|c|c|c|c|}
\hline & Atlanta & $\begin{array}{l}\text { Los } \\
\text { Angeles }\end{array}$ & Berlin & London \\
\hline People per $\mathrm{km}^{2}$ (average) & 580 & 1,870 & 3,930 & 4,120 \\
\hline GDP per capita $(\$)$ & 54,853 & 60,881 & 37,147 & 54,304 \\
\hline Private motorised mode share $(\%)$ & 92 & 88 & 32 & 33 \\
\hline $\begin{array}{l}\text { Population living } 500 \mathrm{~m} \text { from rail based } \\
\text { public transport network (\%) }\end{array}$ & 5 & 12 & 33 & 36 \\
\hline
\end{tabular}

Transport and telecommunications: A number of specific interactions between the telecommunications and transport systems and their use are now recognised (Mokhtarian, 2003; Mokhtarian, 2009; Lyons, 2015; see also Section 2): substitution (use of the telecommunications system can replace use of the transport system for the person gaining access); stimulation (use of the telecommunications system can give rise to additional use of the transport system); supplementarity (use of the telecommunications system for access replaces the need for growth in the use of the transport system in order to increase overall access); redistribution (use of the telecommunications system changes where and when the transport system is used even if the total amount of use of the latter is unaltered); enrichment (the telecommunications system is used at the same time as using the transport system); operational efficiency (use of the telecommunications system enables more effective use of the transport system thereby improving access); and indirect effects (opportunity enabled by the telecommunications system leads to changes to social and/or business practices which in turn (and over time) lead to impacts on the use of the transport system). With so many interactions at work (and continuing to evolve over time as digital connectivity opportunities continue to develop) a key challenge is being able to understand the combined 'net' effect of one system on the other.

Land-use and telecommunications: During the evolution of the telecommunications system, some commentators foresaw the 'death of distance'. In other words, the 'cost' of physically travelling in order to overcome spatial separation would be diminished (or even removed) through the near instantaneous connectivity afforded by telecommunications. Consideration has concerned "whether the impacts of ICT on urban form are centrifugal or centripetal" (Maeng and Nedović-Budić, 2008: 5). In other words, would telecommunications bring about an outwards force on urban form development or a gravitational pull towards the centre? As the land use system and telecommunications systems have evolved, Page and Phillips (2003: 73) suggest a "co-mingling of electronic and physical space" taking place. At the level of the individual or individual organisation, then, instances of both centrifugal and centripetal impacts on spatial location are likely to be taking place. However, there is a compelling sense that the telecommunications system is performing a complementary role to the trend in urbanisation whereby physical proximity is accompanied by digital connectivity. This concept has been referred to as 'live local, act global" or as Page and Phillips (2003: 81) put it, "wired skyscrapers are more connected to similar buildings in Tokyo and London than to their own neighbourhoods". 
The evolution of urban metabolisms will be strongly linked to how the design and use of the land use, transport and telecommunications systems develop over time in pursuit of maintaining and improving access. As we have already noted, different accessibility pathways have been followed, leading to different urban metabolisms. Such pathways have been governed by supply and demand associated predominantly with land-use and transport interactions. It is now necessary to factor in the effects of the digital age into the shaping of new accessibility pathways into the future. This will have significant consequences for the nature and scale of flows of material and nonmaterial resources and wastes.

It should ultimately be acknowledged that we can be, and are, agents of change in influencing the accessibility pathway we follow. We will return to this in the final section of the paper. However, there is also a need to acknowledge that we are in a time of uncertainty regarding what people in future will want to do and what they will be able to do which together will strongly influence urban metabolism. It is then helpful to embrace and expose such uncertainty in order that policymakers in particular can determine how best to steer urban development in ways that embody flexibility and resilience to accommodate uncertainty and assure the sustainability of urban metabolism. An approach for doing so is scenario planning, which we now briefly consider in terms of a recent example of relevance.

\subsection{Embracing, exposing and responding to uncertainty}

In times of 'deep uncertainty' (Marchau et al., 2010) it is important to entertain significant departure from 'business as usual' trend extrapolations and embrace the uncertainty faced through the use of scenario planning (Davidson, 2014). Scenario planning aims to expose uncertainty through the development of plausible divergent future scenarios.

A recent scenario planning exercise (which had lifestyles, accessibility and mobility as its focus) was undertaken by the New Zealand Ministry of Transport (Lyons et al., 2014). It sought to explore how the transport system could or should evolve in order to support mobility in the future. It developed a set of four scenarios based upon the interaction of two critical uncertainties: the relative preference for connectivity in society between physical (transport system) and virtual (telecommunications system); and the relative cost of energy (whose uncertainty was underlined by the sharp drop in world crude oil prices during 2014). The resulting scenarios are depicted in Figure 2. 


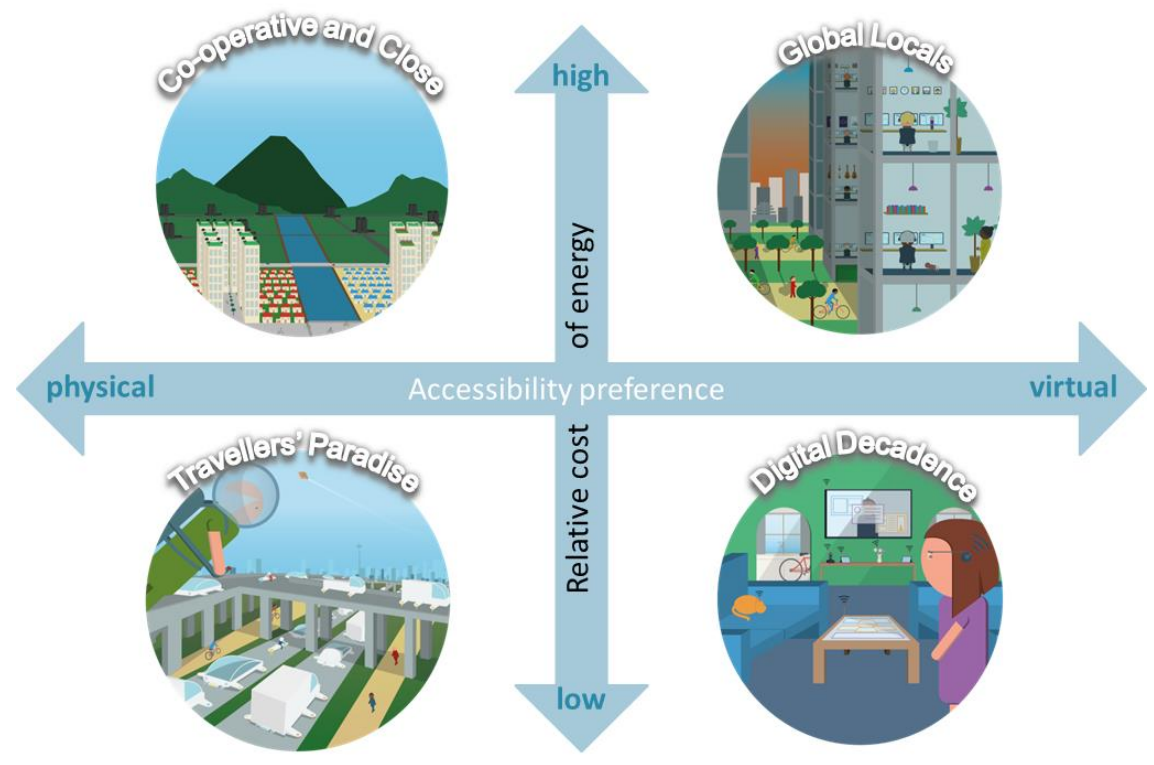

If lifestyle preferences are oriented towards face-to-face interaction, and transcending distance for such interactions is relatively cheap in energy terms then we could face relaxed spatial constraints and intensified flows in relation to physical mobility (Travellers' Paradise). If such lifestyle preferences exist in the face of the 'constraints' of high relative cost of energy then the importance of proximity will be intensified in relation to lifestyle expression. This would be alongside a need for resource efficiency that could lead towards urban societies which use motorised mobility more sparingly and perhaps strongly espouse collaborative consumption with greater dependence on active travel modes (Co-operative and Close). Meanwhile if lifestyle preferences are oriented more strongly towards forms of digital connectivity then flows of digital resources become more pronounced and important with a lessening of motorised mobility in terms of personal travel. Depending upon whether or not the relative cost of energy is high or low, urban development may also be strongly reliant on proximity in a society of living local and acting global (Global Locals) or affordable energy may mean that locational constraints are relaxed alongside a preference for digital connectivity which may maintain requirements for strong flows of physical mobility either within or between cities and between cities and rural areas (Digital Decadence).

If one considers that such divergent future scenarios are indeed plausible then it demands of policymakers that they look to develop approaches to shaping urban development that is then able to accommodate the uncertainties ahead. Urban development pathways will depend significantly upon the path of development to date for a given city and the nature and scale of urban form that already exists. However, broadly speaking it would seem appropriate to encourage 'whole system' thinking which looks to co-evolve facilitation of spatial proximity, digital connectivity and physical mobility to create urban systems that spread their reliance for access across the transport, land use and telecommunications systems. In this way unknowns associated with future lifestyles and supply side constraints that ultimately determine lifestyle expression can be accommodated. 


\section{Conclusions and research agenda}

In this paper we have emphasised the centrality of lifestyles to urban metabolism, particularly in the context of digitalization and the (re-)emergence of a sharing economy. We have sought to illustrate some of the many complexities and dynamics that exist in terms of how lifestyle expression possibilities are developing. The paper demonstrates that, as a result, we face significant challenges in being able to better understand how lifestyles and lifestyle expressions are being affected by drivers of change associated with the digital age and cultural changes. The inadequacy of our understanding - exacerbated by the many different drivers at play - places us in a situation of deep uncertainty when looking to make sense of how urban metabolism may be developed in the future. Indeed we are even struggling to make sense of the dynamics and makeup of behaviours accompanying lifestyle expressions presently associated with the two key phenomena of urban digitalization and collaborative consumption. As a result we reach a conclusion that we must focus attention on exposing the uncertainties concerning future lifestyle and lifestyle expressions and take steps to develop a three-pronged system of accessibility (physical mobility, proximity and digital connectivity) which provides flexibility and resilience and which at same time stimulates sustainable urban metabolism.

We would suggest that policymakers must have greater confidence in the flexibility of this three-pronged system of access and be prepared to take stronger steps to influence lifestyle expressions (demand) through the way in which the supply associated with the land use, transport and telecommunications system is invested in, developed, and managed. For instance, development planning policy can dampen or amplify the centrifugal or centripetal forces of ICTs on lifestyle expression. Such forces can also be affected by regulatory or market incentives to invest in urban telecommunications infrastructure and connection. While today's rapid developments in collaborative consumption are largely steered by market forces, policymakers could, and we would argue should, take a more proactive role to stimulate elements of collaborative consumption that lead to a more socially and environmentally sustainable urban metabolism, while strategically regulating elements that hamper such developments. Pricing of transport system use - while politically contentious - can change the spatio-temporal planning of activities by individuals and organisations and related decisions on whether, when, how (including sharing) or whether or not to travel. Policymakers must contend with path dependency (with stark differences between existing cities as noted in Table 2), but they are nevertheless significant agents in the forward shaping of accessibility pathways. They must be alert to the rebound effects of supply and demand-side changes. Perhaps their greatest consideration is how to suppress rebound effects by taking steps to lock in the benefits for urban metabolism that digitalization and the sharing economy make possible, subject to alignment with lifestyles.

This will of course remain highly challenging in democratic societies. Yet it should not imply that strong governance of our urban realm is necessarily at odds with freedom of choice, adaptive human behaviour, market forces and lifestyle expressions that may be changing significantly in any case and which might further be changed.

Based on our observations of the complexities and large uncertainties related to lifestyle changes and their implications for urban metabolism, we have set up a 
research agenda for substantive as well as methodological issues. The importance of interdisciplinary collaboration in pursuit of this research should be stressed.

Substantive issues we suggest include the need to examine the following:

- implications of increasing use of (mobile) ICTs for size, nature and spatiotemporal consumption of energy and resources and waste production;

- collaborative consumption initiatives and their potential energy and resource savings and their implications for flows of material and non-material resources and waste;

- inequalities in opportunities to change lifestyles and/or lifestyle expression, in particular in the use of ICTs and participation in collaborative consumption, and their implications for size, nature and spatio-temporal consumption of energy and resources and waste production; and

- effectiveness of policies to stimulate sustainable urban metabolism via facilitating specific types of ICTs and collaborative consumption.

Meanwhile, important methodological issues need to be considered:

- The nature of behavioural studies needs to change. To date a dominant approach has been that of largely quantitative surveys, statistical analysis and modelling. This should remain a contributory element but is clearly limited given the complexity of the behaviours being examined.

- There should be a more equal weight given to mixed method approaches, in which quantitative and qualitative (e.g. ethnographic studies on lifestyles in environments) approaches will contribute jointly to knowledge.

- There is a need for panel studies that can track individuals over time and better understand the dynamics of behaviour change and changes in environments at the individual level.

- Understanding changing (adjective) lifestyles is important but so too is a need for more research into possibilities for changing (verb) lifestyles. Both of these are likely to demand participatory methodologies that engage multiple stakeholders and experts such as through Delphi studies, scenario planning, personalized travel planning, gamification and other behavioral economics approaches such as social marketing.

\section{References}

Abley, S. and Halden, D. (2013). The New Zealand accessibility analysis methodology. NZ Transport Agency research report 512, March.Berrington, A. and Mikolai, J. (2014). Young Adults' Licence Holding and Driving Behaviour in the UK. RAC Foundation, London.

Aguiar, M. and Hurst, E. (2009) A Summary of Trends in American Time Allocation: 1965-2005. Social Indicators Research, 93, 57-64.

Alexander, B., Ettema, D. and Dijst, M. (2010) Fragmentation of Work Activity as a Multi-dimensional Construct and its Association with ICT, Employment and Sociodemographic Characteristics. Journal of Transport Geography 18, 5564.

Alexander, B., Hubers, C.G.T.M., Schwanen, T., Dijst, M.J. and Ettema, D.F. (2011). Anything, anywhere, anytime? Developing measurement instruments to assess 
the spatial and temporal fragmentation of activities. Environment and Planning B: Planning and Design, 38 (4), 678-705.

Bardhi, F. and Eckhardt, G. M. (2012). Access-based consumption: The case of car sharing. Journal of Consumer Research, 39(4), 881-898.

Belk, R. (2007). Why not share rather than own? Annals, AAPSS, 611, 126-140.

Belk, R. (2014a). Sharing versus pseudo-sharing in web 2.0. The Anthropologist, 4(2).

Böcker, L. and Meelen, T. (2017). Sharing for people, planet or profit? Analysing motivations for intended sharing economy participation. Environmental Innovation and Societal Transitions, 23, 28-39.

Botsman, R. (2013). The sharing economy lacks a shared definition. http://www.collaborativeconsumption.com/2013/11/22/the-sharing-economylacks-a-shared-definition/.

Botsman, R. and Rogers, R. (2010). What is mine is yours: the rise of collaborative consumption. New York: HarperCollins Publishers.

Burkhardt, J. E. and Millard-Ball, A. (2006). Who is attracted to carsharing? Transportation Research Record: Journal of the Transportation Research Board, 1986(1), 98-105.

Burnett, L. (2014). The sharing economy: where we go from here? http://www.slideshare.net/LeoBurnettWorldwide/the-us-sharing-economy-leoburnett-report-final.

Celsor, C. and Millard-Ball, A. (2007). Where does carsharing work?: Using geographic information systems to assess market potential. Transportation Research Record: Journal of the Transportation Research Board, 1992(1), 6169.

Circella, G., Mokhtarian, P.L. and Poff, L.K. (2012). A Conceptual Typology of Multitasking Behavior and Polychronicity Preferences. electronic International Journal of Time Use Research 9(1), 59-107.

Cornelis, I., Van Hiel, A., Roets, A. and Kossowska, M. (2009). Age differences in conservatism: Evidence on the mediating effects of personality and cognitive style. Journal of Personality, 77(1), 51-88.

Couclelis, H. (2000). From Sustainable Transportation to Sustainable Accessibility: Can We Avoid a New 'Tragedy of the Commons'? In D. Janelle and D. Hodge (eds.), Information, Place, and Cyberspace: Issues in Accessibility. Berlin: Springer-Verlag, 341-356.

Crutzen, P.J. (2002). Geology of mankind. Nature, 415, January, 23.

Cullinane, S. (2009). From Bricks to Clicks: The Impact of Online Retailing on Transport and the Environment. Transport Reviews, 29(6), 759-776.

Czaja, S. J., Charness, N., Fisk, A. D., Hertzog, C., Nair, S. N., Rogers, W. A. and Sharit, J. (2006). Factors predicting the use of technology: Findings from the center for research and education on aging and technology enhancement (CREATE). Psychology and Aging, 21(2), 333.

Davidson, C. (2014). Future Demand - Insights into the scenario planning methodology. New Zealand Ministry of Transport, Wellington, New Zealand, November. www.transport.govt.nz/futuredemand

Delbosc, A. and Currie, G. (2013). Causes of Youth Licensing Decline: A Synthesis of Evidence. Transport Reviews, 33(3) - Special Issue on Peak Car, 271-290.

Deng, H., Mokhtarian, P.L. and Circella, G. (2015). Modeling the Adoption of Fullday, Part-day and Overtime Telecommuting: An Investigation of Northern California Workers Using Non-Mean-Centered Factor Scores to Segment on Built Environment Attitudes. Under review; available from the authors. 
Dubois, G., Peeters, P., Ceron, J.-P. and Gossling, S. (2011). The Future Tourism Mobility of the World's Population: Emission Growth versus Climate Policy. Transportation Research A, 45, 1031-1042.

Duncan, M. (2011). The cost saving potential of carsharing in a US context. Transportation, 38(2), 363-382.

Farrington, J. (2007). The new narrative of accessibility: its potential contribution to discourses in (transport) geography. Journal of Transport Geography, 15, 319330.

Fishman, E. (2015). Bikeshare: A review of recent literature. Transport Reviews, 122.

Fraiberger, S. P. and Sundararajan, A. (2015). Peer-to-Peer Rental Markets in the Sharing Economy. NYU Stern School of Business Research Paper.

Freathy, P. and Calderwood, E. (2013). The Impact of Internet Adoption upon the Shopping Behaviour of Island Residents. Journal of Retailing and Consumer Services, 20, 111-119.

Gansky, L. (2010). The mesh: Why the future of business is sharing. New york: Penguin.

Geurs, K.T. and van Wee, B. (2004). Accessibility evaluation of land-use and transport strategies: review and research directions. Journal of Transport Geography, 12, 127-140.

Goodwin, P. (2012). Peak travel, peak car and the future of mobility: Evidence, unresolved issues, policy implications, and a research agenda. International Transport Forum round table on "Long Run Trends in Travel Demand", Paris, OECD.

http://www.internationaltransportforum.org/jtrc/DiscussionPapers/DP201213. pdf

Goodwin, P. and Van Dender, K. (2013). 'Peak Car' - Themes and Issues. Transport Reviews, 33(3) - Special Issue on Peak Car: 243-254.

Graham, D. (2006). Investigating the link between productivity and agglomeration for $U K$ industries. A report to the Department for Transport.

Grassmuck, V. R. (2013). The sharing turn: Why we are generally nice and have a good chance to cooperate our way out of the mess we have gotten ourselves into. In. Sützl, W., Stalder, F., Maier, R. and Hug, T. (Eds.), Cultures and ethics of sharing, Innsbruck University Press, Innsbruck.

Haddad, H., Lyons, G. and Chatterjee, K. (2009). An examination of determinants influencing the desire for and frequency of part-day and whole-day homeworking. Journal of Transport Geography, 17, 124-133.

Haefeli, U., Matti, D., Schreyer, C., Maibach, M. (2006). Evaluation Carsharing. Final Report. Study commissioned by the Bundesamt für Energie BFE, Switzerland.

Hald, M., Christiansen, P. and Nenseth, V. (2011). Bildeling i hovedstadsområdet, [Car sharing in the metropolitian area of Oslo]. TØI-report 1156/2011. Oslo, Institute of transport economics.

Hamari, J., Sjöklint, M. and Ukkonen, A. (2013). The sharing economy: Why people participate in collaborative consumption. Working Paper. Available at: http://papers.ssrn.com/sol3/papers.cfm?abstract id=2271971.

Hawlitschek, F., Teubner, T. and Gimpel, H. (2016) Understanding the sharing economy - drivers and impediments for participation in peer-to-peer rental. $49^{\text {th }}$ Hawaii International Conference on System Sciences (HICSS), pp. $4782-$ 4791. DOI: 10.1109/HICSS.2016.593 
He, S. and Hu, L. (2015). Telecommuting, Income, and Out-of-home Activities. Travel Behaviour and Society, 2(3), 131-147.

Hesse, M. (2002). Shipping News: The Implications of Electronic Commerce for Logistics and Freight Transport. Resources, Conservation and Recycling, 36, 211-240.

Hubers, C., Schwanen, T. and Dijst, M. (2008). ICT and Temporal Fragmentation of Activities: An Analytical Framework and Initial Empirical Findings. Tijdschrift voor Economische en Sociale Geografie, 99(5), 528-546.

Imbens, G.W. and Rubin, D. B. (2015). Causal Inference in Statistics, Social, and Biomedical Sciences. Cambridge, UK: Cambridge University Press.

Kent, J.L. (2013). Carsharing as active transport: What are the potential health benefits? Journal of Transport and Health, 1(1), 54-62.

Kenyon, S., Rafferty, J. and Lyons, G. (2003). Social exclusion and transport: a role for virtual accessibility in the alleviation of mobility-related social exclusion? Journal of Social Policy, 32(3), 317-338.

Kuroda, S. (2010). Do Japanese Work Shorter Hours than Before? Measuring Trends in Market Work and Leisure Using 1976-2006 Japanese Time-use Survey. Journal of the Japanese and International Economics 24, 481-502.

Le Vine, S. and Jones, P. (2012). On the Move: Making sense of car and train travel trends in Britain. RAC Foundation, London.

Litman, T. (2000). Evaluating carsharing benefits. Transportation Research Record: Journal of the Transportation Research Board, 1702(1), 31-35.

Lyons, G. (2015). Transport's Digital Age Transition. Journal of Transport and Land Use, 8(2), 1-19.

Lyons, G., and Goodwin, P. (2014). Grow, peak or plateau - the outlook for car travel. Report of a roundtable discussion in London on 20 May 2014, New Zealand Ministry of Transport, July. http://eprints.uwe.ac.uk/23277/

Lyons, G., Davidson, C., Forster, T., Sage, I., McSaveney, J., MacDonald, E., Morgan, A., and Kole, A. (2014). Future Demand: How could or should our transport system evolve in order to support mobility in the future? Final Report. New Zealand Ministry of Transport, Wellington, New Zealand, November. www.transport.govt.nz/futuredemand

Lyons, G. and Davidson, C. (2016). Guidance for transport planning and policymaking in the face of an uncertain future. Transportation Research Part A: Policy and Practice, 88, 104-116.

Maeng, D-M. and Nedović-Budić, Z. (2008). Urban form and planning in the information age: lessons from the literature. Spatium, 17-18, 1-12.

Marchau, V. A. W. J., Walker, W. E., and van Wee, G. P. (2010). Dynamic adaptive transport policies for handling deep uncertainty. Technology Forecasting \& Social Change, 77, 940-950.

Martin, E. W., and Shaheen, S. A. (2011). Greenhouse gas emission impacts of carsharing in north america. Intelligent Transportation Systems, IEEE Transactions, 12(4), 1074-1086.

Martin, E., Shaheen, S. A. and Lidicker, J. (2010). Impact of carsharing on household vehicle holdings. Transportation Research Record, 2143(1), 150-158.

Mateyka, P.J., Rapino, M.A. and Landivar, L.C. (2012). Home-Based Workers in the United States: 2010. Household Economic Studies P70-132, U. S. Department of Commerce, U. S. Census Bureau, October. Available at https://www.census.gov/prod/2012pubs/p70-132.pdf. 
Matthews, H.S., Hendrickson, C.T. and Soh, D.L. (2001) Environmental and Economic Effects of E-commerce: A Case Study of Book Publishing and Retail Logistics. Transportation Research Record, 1763, 6-19.

Meelen, T., Böcker, L., Glind, van der, P., Frenken, K., Giezen, M. (2015). Who shares what? A large-scale survey on willingness to participate in multiple sharing economies. Paper presented at the Association of American Geographers annual meeting. In progress.

Millard-Ball, A., Murray, G., Schure, J., Fox, C. and Burkhardt, J. (2005). CarSharing: Where and How it Succeeds. TCRP Report 108, Transportation Research Board, Washington DC.

Mokhtarian, P.L. (2003). Telecommunications and Travel - The Case for Complementarity. Journal of Industrial Ecology, 6(2) - E-commerce, the Internet and the Environment, 43-57.

Mokhtarian, P.L. (2004) A Conceptual Analysis of the Transportation Impacts of B2C E-Commerce. Transportation, 31(3), 257-284.

Mokhtarian, P.L. (2009). If telecommunication is such a good substitute for travel, why does congestion continue to get worse? Transportation Letters, 1, 1-17.

Mokhtarian, P.L. and Tal, G. (2013). Impacts of ICT on Travel Behavior: A Tapestry of Relationships. In J.-P. Rodrigue, T. Notteboom and J. Shaw (eds.), The Sage Handbook of Transport Studies. London: Sage Publications, 241-260.

Mokhtarian, P.L., Salomon, I. and Choo, S. (2005). Measuring the Measurable: Why Can't we Agree on the Number of Telecommuters in the US? Quality and Quantity, 39(4), 423-452.

Mokhtarian, P.L., Salomon, I. and Handy, S.L. (2006) The Impacts of ICT on Leisure Activities and Travel: A Conceptual Exploration. Transportation, 33(3), 263289.

Napoli, P. M. and Obar, J.A. (2013). Mobile Leapfrogging and Digital Divide Policy: Assessing the Limitations of Mobile Internet Access. Fordham University Schools of Business Research Paper No. 2263800. Available at http://papers.ssrn.com/sol3/papers.cfm?abstract id=2263800.

Nasi, M., Rasanen, P. and Sarpila, O. (2012). ICT Activity in Later Life: Internet Use and Leisure Activities amongst Senior Citizens in Finland. European Journal of Ageing, 9, 169-176.

Nielsen (2014). Is sharing the new buying? Reputation and trust are emerging as new currencies.

http://www.nielsen.com/content/dam/nielsenglobal/apac/docs/reports/2014/Ni elsen-Global-Share-Community-Report.pdf

Ozanne, L. K. and Ozanne, J. L. (2011). A child's right to play: the social construction of civic virtues in toy libraries. Journal of Public Policy \& Marketing, 30(2), 264-278.

Page, S. and Phillips, B. (2003). Telecommunications and urban design. City: analysis of urban trends, culture, theory, policy, action, 7(1), 73-94.

Pearce, K.E. and Rice, R.E. (2013) Digital Divides from Access to Activities: Comparing Mobile and Personal Computer Internet Users. Journal of Communication, 63, 721-744.

Piscicelli, L., Cooper, T. And Fisher, T. (2015). The role of values in collaborative consumption: insights from a product-service system for lending and borrowing in the UK. Journal of Cleaner Production, 97, 21-29.

Rifkin, J. (2000). The age of access: the new culture of hypercapitalism where all of life is a paid-for experience. New York: Penguin. 
Rifkin, J. (2014). The zero marginal cost society: the internet of things, the collaborative commons and the eclipse of capitalism. New York: Palgrave/Macmillan.

Robinson, J. P. and Martin, S. (2010). IT Use and Declining Social Capital? More Cold Water from the General Social Survey (GSS) and the American TimeUse Survey (ATUS). Social Science Computer Review, 28(1), 45-63.

Rode, P., Floater, G., Thomopoulos, N., Docherty, J., Schwinger, P., Mahendra, A. and Fang, W. (2014). Accessibility in Cities: Transport and Urban Form. NCE Cities Paper 03. LSE Cities. London School of Economics and Political Science.

Rogers, E. M. (2010). Diffusion of innovations Simon and Schuster.

Schwanen, T., Dijst, M.J. and Kwan, M.-P. (2008). ICTs and the uncoupling of acitivities, places and times. Tijdschrift voor Economische en Sociale Geografie, 99 (5), 519-527.

SEU (2003). Making the Connections: Final Report on Transport and Social Exclusion. February, Social Exclusion Unit.

Shaheen, S. A., and Cohen, A. P. (2007). Growth in worldwide carsharing: An international comparison. Transportation Research Record, 1992(1), 81-89.

Shaheen, S. A., Cohen, A. P., and Chung, M. S. (2009). North American Carsharing. Transportation Research Record, 2110(1), 35-44.

Shareable (2012). Gen Y and the sharing economy. Available at: http://www.shareable.net/blog/gen-y-and-the-sharing-economy

Sioui, L., Morency, C., and Trépanier, M. (2013). How Carsharing Affects the Travel Behavior of Households: A Case Study of Montréal, Canada. International Journal of Sustainable Transportation, 7(1), 52-69.

Sobh, R., and Belk, R. (2011). Domains of privacy and hospitality in Arab Gulf homes.Journal of Islamic Marketing, 2(2), 125-137.

Steffen, W., Crutzen, P.J. and McNeill, J.R. (2007), The Anthropocene: Are Humans Now Overwhelming the Great Forces of Nature. AMBIO: A Journal of the Human Environment, 36(8), 614-621.

The Atlantic (2012). The cheapest generation. Available at: http://www.theatlantic.com/magazine/archive/2012/09/the-cheapestgeneration/309060/

Thulin, E. and Vilhelmson, B. (2005). Virtual Mobility of Urban Youth: ICT-based Communication in Sweden. Tijdschrift voor Economische en Sociale Geografie, 96(5), 477-487.

Tussyadiah, I.P. (2015). An exploratory study on drivers and deterrents of collaborative consumption in travel. In Tussyadiah, I. and Inversini, A. (Eds.), Information \& communication technologies in tourism 2015. Switzerland: Springer International Publishing.

Tussyadiah, I. P., and Pesonen, J. (2015). Impacts of Peer-to-Peer Accommodation Use on Travel Patterns. Journal of Travel Research, 0047287515608505.

United Nations Environment Programme in 2012, Global Environment Outlook 5, Nairobi, Kenya. http://www.unep.org/geo/geo5.asp.

USDOT (1997). Our Nation's Travel: 1995 NPTS Early Results Report. Federal Highway Administration, September.

USDOT (2015). Passenger Travel Facts and Figures 2015. Available at http://www.rita.dot.gov/bts/sites/rita.dot.gov.bts/files/PTFF\%20August 2015. pdf. 
Urry, J., Birtchnell, T., Caletrio, J. and Pollastri, S. (2014). Living in the City. Foresight Future of Cities Project, Government Office for Science, London, June.

United Nations Environment Programme (2012). Global Environment Outlook 5, Nairobi, Kenya.

Van Acker, V., Goodwin, P. and Witlox, F. (2014). Key Research Themes on Travel Behaviour, Lifestyle and Sustainable Urban Mobility. International Journal of Sustainable Transportation.

Van der Waard, J., Jorritsma, P. and Immers, B. (2013). New Drivers in Mobility; What Moves the Dutch in 2012? Transport Reviews, 33(3) - Special Issue on Peak Car, 343-359.

Van Wee, B. (2015). Peak car: the first signs of a shift to ICT-based activities replacing travel? A discussion paper. Transport Policy, 42, 1-3.

Visser, E.-J. and M. Lanzendorf (2004). Mobility and Accessibility Effects of B2C Ecommerce: A Literature Review. Tijdschrift voor Economische en Sociale Geografie, 95(2), 189-205.

White, N.R. and White, P. B. (2007) Home and Away: Tourists in a Connected World. Annals of Tourism Research, 34(1), 88-104.

Wilke, S., Böhler, D., Bongardt, C., and Schäfer-Sparenberg (2007). Zukunft des Carsharing in Deutschland. Wuppertal Institute for Climate, Environment and Energy, Wuppertal.

Williams, E. and Tagami, T. (2003). Energy Use in Sales and Distribution via Ecommerce and Conventional Retail: A Case Study of the Japanese Book Sector. Journal of Industrial Ecology, 6(2), 99-114.

Wrigley, N. and Lambiri, D. (2015). British High Streets: from Crisis to Recovery? A Comprehensive Review of the Evidence. Economic and Social Research Council, March. Available at http://eprints.soton.ac.uk/375492/1/BRITISH\%20HIGH\%20STREETS MAR CH2015\%28V2\%29.pdf.

Zhou, B. and Kockelman, K. M. (2011). Opportunities for and impacts of carsharing: A survey of the Austin, Texas market. International Journal of Sustainable Transportation, 5(3), 135-152.

Zhu, P. (2012). Are telecommuting and personal travel complements or substitutes? The Annals of Regional Science, 48(2), 619-639. 